\title{
Surgical management of lymphedema: a review of current literature
}

\author{
Kitae E. Park, Omar Allam, Ludmila Chandler, Mohammad Ali Mozzafari, Catherine Ly, Xiaona Lu, \\ John A. Persing
}

Division of Plastic and Reconstructive Surgery, Yale University School of Medicine, New Haven, CT, USA

Contributions: (I) Conception and design: All authors; (II) Administrative support: All authors; (III) Provision of study materials or patients: All authors; (IV) Collection and assembly of data: All authors; (V) Data analysis and interpretation: All authors; (VI) Manuscript writing: All authors; (VII) Final approval of manuscript: All authors.

Correspondence to: John A. Persing, MD. 330 Cedar Street, New Haven, CT 06520, USA. Email: John.persing@yale.edu.

\begin{abstract}
Lymphedema may be characterized by a progressive clinical course and limitations in improvement despite multi-modality treatment. In westernized countries, it most commonly presents as an undesirable complication of cancer treatment, particularly breast cancer. In the past several decades, surgical treatments for lymphedema have advanced, alongside developments in microsurgery. Lymphovenous anastomosis (LVA) and lymph node transplantation are physiological therapies that may reduce lymphedema through addressing its route cause. Ablative techniques such as liposuction and subcutaneous excision aid in resolving the accumulation of proteinaceous adipose and fibrotic tissue seen in advanced lymphedema. The goal of this review is to examine the outcomes and limitations of current surgical techniques used in lymphedema management.
\end{abstract}

Keywords: Lymphedema; lymph node transfer; lymphovenous anastomosis (LVA); liposuction

Submitted Jan 07, 2020. Accepted for publication Feb 17, 2020.

doi: 10.21037 /gs.2020.03.14

View this article at: http://dx.doi.org/10.21037/gs.2020.03.14

\section{Introduction}

Lymphedema is a condition characterized by accumulation of protein-rich fluid in the interstitial space and consequent tissue swelling. Early stages may have physical findings and symptoms of painless pitting edema, discomfort, and heaviness of the limb, especially after continued use (1). However, as time passes without treatment, the condition progresses to fibrosis, thickening of the skin, and irreversible non-pitting edema. Patients experience a higher rate of chronic skin conditions as well, such as recurrent cellulitis, ulceration and impetigo (2). The etiology of lymphedema is classified as either primary or secondary. Primary lymphedema occurs due to a congenital anomaly or absence of the lymphatic system in certain populations. First symptoms of primary lymphedema usually occur between the ages of 10 to 25 years, with a reported prevalence of approximately $1 / 100,000(3,4)$. Secondary lymphedema occurs due to an acquired impairment in lymphatic flow. Common etiologies include trauma, chronic infection, and malignancy (3). The most common cause, in westernized countries, is treatment of malignancy, particularly breast cancer (5). Studies have reported the incidence of upper extremity lymphedema following axillary lymph node dissection in the range of $7 \%$ to $45 \%$ depending on risk factors and supplemental use of adjuvant radiation therapy (6).

First line intervention of lymphedema includes conservative measures, such as complete decongestive therapy (CDT). CDT is a multidisciplinary treatment approach involving exercise, daily bandaging, manual drainage therapy and skin care. The intervention occurs as a 2 phase approach, with phase 1 focusing on reduction of lymphedema volume, and phase 2 focusing on maintenance of the reduced volume (7). CDT can be an effective treatment for lymphedema in all stages of the disease (8-10). However, limitations include the need for strong patient 
compliance, the need of life-long compression garment use, and the high cost associated with prolonged adjunctive therapy, such as skin care and laser treatment (9-12).

Surgical treatment of lymphedema is suggested when conservative management fails, particularly early following the onset of the swelling. The field of lymphedema surgery is a constantly evolving field. Early techniques in management of lymphedema include ablative procedures such as the Homans or Charles procedures, which involve excision of the subcutaneous tissue beneath the affected skin and covering the defect with skin flaps or a full or split-thickness grafts $(13,14)$. Advances in microsurgical techniques have allowed the advent of more physiologic and effective methods such as vascularized lymph node transplant (VLNT) or lymphovenous anastomosis (LVA). The purpose of this review is to provide an analysis of current techniques in lymphedema management, specifically related to their outcomes and limitations.

\section{Methods}

A review of peer-reviewed literature was performed on PubMed-MEDLINE to evaluate current strategies in surgical management of lymphedema. Initial query was performed using a combination of the terms "lymphedema," "surgery," "lymphovenous anastomosis", "lymph node transfer," and "liposuction". Additional queries were performed based on relevant references of the searched articles as well.

\section{Physiological therapy}

Surgical techniques of lymphedema management can broadly be divided into physiologic therapy and ablative therapy. Physiologic surgical techniques are microsurgical procedures that foster the physiologic drainage of lymphatic fluid through anastomosis of lymphatic vessels with the venous system, or the incorporation of a functional lymph node in the region of ablative treatment.

\section{LVA}

LVA was first described in the 1960s (15-17). Nielubowicz and Olszewski performed the procedure in 4 patients with secondary lower extremity lymphedema, and showed persistent limb circumference reduction over 1 to 9 month follow-up (16). In this technique, the surgeon forms an artificial connection between a patent lymphatic vessel and adjacent venules to redirect lymphatic flow, allowing the lymphatic fluid to bypass obstructed lymphatic vessels. The anastomosed vessels have diameters ranging from 0.1 to $0.8 \mathrm{~mm}$, requiring supermicrosurgical technique $(18,19)$. Recent use of indocyanine green (ICG) lymphography pre and intraoperatively to visualize patent lymphatic vessels has allowed for restoration of lymphatic flow using minimally invasive procedures, rendering LVA as an attractive option in early stage lymphedema $(20,21)$.

Since its introduction, several studies have examined the outcomes of LVA (22-24). In a prospective study of 100 patients with secondary upper or lower extremity lymphedema, Chang et al. (2013) found a $61 \%$ reduction in upper extremity volume in patients with stage 1 or 2 lymphedema according to the MD Anderson lymphedema classification, compared to a $17 \%$ mean volume reduction in patients with stage 3 or 4 lymphedema (Table 1) (25). These results suggest that LVA is more effective in early stages of lymphedema, rather than at later stages when irreversible tissue fibrosis has occurred and lymphatic smooth muscle is dysfunctional. These authors also found that results were not as good for lower extremity lymphedema, with only $57 \%$ of patients reporting symptom improvement compared to $96 \%$ of patients who received LVA for the upper extremity. The large size and constantly dependent nature of lower extremities may make them less likely to improve in symptoms in comparison to the upper extremity (25). Given its efficacy in secondary lymphedema management, some have begun performing prophylactic LVA at the time of initial axillary dissection $(26,27)$. In a meta-analysis Jørgensen et al. (2018) found that prophylactic LVA at the time lymphadenectomy reduced the risk of lymphedema by $77 \%$ compared to no prophylactic procedure $(\mathrm{P}<0.0001)(27)$.

Cheng et al. (2018) demonstrated the effectiveness of LVA in primary lymphedema as well (28). Although a sample size of 4 , patients with congenital forms of lymphedema who received LVA experienced roughly 4 times/year fewer episodes of cellulitis, and self-reported increases in quality of life, appearance, symptoms, function, and mood (28). The author does suggest that other techniques such as VLNT may be more beneficial in primary lymphedema, as the congenital absence or occlusion of lymphatics in the case of primary lymphedema often preclude LVA as an option.

Despite the positive outcomes, there are still limitations to the technique. LVA relies on there being a patent lymphatic vessel, so its applicability may be limited in patients with congenital lymphedema or late stage 
Table 1 Lymphedema classification systems in literature

\begin{tabular}{|c|c|c|}
\hline Classification system & Stage & Characteristics \\
\hline \multirow{2}{*}{$\begin{array}{l}\text { M.D. Anderson staging } \\
\text { system }\end{array}$} & 3 & $\begin{array}{l}\text { Reduced number of patent lymphatic vessels with dermal backflow spanning entire arm on } \\
\text { lymphangiography }\end{array}$ \\
\hline & 4 & $\begin{array}{l}\text { No visible patent lymphatic vessels with dermal backflow spanning entire arm and dorsum of hand on } \\
\text { lymphangiography }\end{array}$ \\
\hline \multirow[t]{2}{*}{$\begin{array}{l}\text { Becker et al. (2006) } \\
\text { staging system }\end{array}$} & I & $\begin{array}{l}\text { Early edema with no or less than } 2 \text { infectious episodes, excess arm circumference not more than } 30 \% \text { of } \\
\text { unaffected arm circumference }\end{array}$ \\
\hline & II & $\begin{array}{l}\text { Later stage edema, more than } 2 \text { infectious episodes, excess arm circumference between } 30 \% \text { an } 50 \% \text { of } \\
\text { unaffected arm circumference }\end{array}$ \\
\hline \multirow{3}{*}{$\begin{array}{l}\text { International Society } \\
\text { of Lymphology staging } \\
\text { system }\end{array}$} & I & $\begin{array}{l}\text { Early accumulation of fluid high in protein content with swelling that reduces with limb elevation; } \\
\text { pitting may be present }\end{array}$ \\
\hline & II & Pitting edema with swelling that does not reduce with limb elevation \\
\hline & III & $\begin{array}{l}\text { Lymphostatic elephantiasis; non-pitting edema with skin changes (e.g., acanthosis, increase in thickness), } \\
\text { fat deposition, and fibrosis }\end{array}$ \\
\hline
\end{tabular}

secondary lymphedema. Furthermore, there is still a lack of data regarding the long-term (greater than 5 years) patency of LVA, with most studies limited to a follow-up of 6 months to 2 years (28-30). Higher volume studies with prolonged follow-up are needed to fully understand the efficacy of LVA.

\section{VLNT}

VLNT is a relatively new technique in the treatment of lymphedema. It was first clinically described by Clodius et al. (1982), who transferred a pedicled groin flap with vascularized inguinal lymph nodes to the left lower extremity with partial success in reducing lymphedema (31). With advances in microsurgical techniques, VLNT has, since then, become a popular option of treatment particularly in cases of moderate to advanced lymphedema, where other treatment methods may not have been effective. The technique involves transfer of a vascularized lymph node and surrounding tissue to a region where a lymph node has been removed or lymph flow is impaired. A microsurgical anastomosis is created between recipient site blood supply and the flap, thereby maintaining vascularization of the lymph node. Common donor sites for the lymph nodes include omental, inguinal, mesenteric, lateral thoracic, axillary, gastroepiploic, and submental nodes $(32,33)$. Common recipient sites include the axilla, elbow, wrist, groin, and ankle (34).

Although the exact mechanism through which VLNT works is unclear, there are 2 main theories. The first is that lymph node transfer induces lymphangiogenesis at the recipient site, leading to improved lymphatic flow and alleviation of lymphedema. This theory has been substantiated by animal and human studies that used lymphoscintigraphy to show formation of new lymphatic channels at the recipient site following VLNT $(35,36)$. The second proposed mechanism is that the transferred lymph node acts as a "pump", wicking lymph fluid from the surrounding interstitial space, and projecting it into the efferent venous circulation $(37,38)$. This is based on the observation that ICG dye injected in the tissue surrounding a transferred lymph node can be found in the afferent donor and recipient venules (39). Lin et al. (2009) reasoned that the high-pressure afferent arterial flow to the lymph node flap creates a local pressure gradient that transports adjacent lymphatic fluid towards the transplanted node (37). The fluid is subsequently absorbed into the low-pressure efferent venous anastomosis, thereby reducing lymphedema. 
Reported outcomes of VLNT in literature have been promising. In a retrospective study of 24 patients suffering from post-mastectomy upper extremity lymphedema, Becker et al. (2006) reported decrease in limb circumference in 22 patients with return to normal size in 10 patients (40). Fifteen patients were able to discontinue physiotherapy permanently. All patients in this study were described as stage I or II lymphedema, indicating early to later stages of the condition (Table 1). Batista et al. (2017) performed a retrospective analysis on outcomes of lymph node transfers to 41 total legs of 38 patients with lower extremity lymphedema (41). Of the 23 legs for which lymph node transfer was the sole procedure performed as the treatment of lymphedema, 21 legs showed at least a minor degree of extremity volume reduction. Nine patients' legs demonstrated greater than $30 \%$ volume reduction when compared to the healthy, unaffected leg (41). Only 2 patients of the VLNT cohort experienced complete resolution of lymphedema, with a lower post-surgical volume in the affected lower extremity than the unaffected extremity. An advantage that VLNT has over LVA is that it can be performed in the absence of patent lymphatic vessels at the recipient site. Leppäpuska et al. (2019) reported outcomes of combined VLNT with liposuction in 21 patients with chronic non-pitting edema (average symptom duration $=52$ months) (42). After an 18 month follow-up, patients experienced an average of $87 \%$ volume reduction in the lymphedematous limb, and reported stabilization of the volume, even during a 7-day cessation of compressive garment therapy (42). Although the volume reduction cannot be attributed to VLNT alone, the findings suggest that VLNT can be an effective treatment in advanced lymphedema, when performed with adjunct ablative procedures.

In patients suffering of post-mastectomy lymphedema, VLNT can be combined with autologous breast repair, thereby reducing surgery time and improving aesthetic outcome. This approach was first described by Saaristo et al. (2012), who performed autologous breast repair with deep inferior epigastric artery perforator (DIEP) and musclesparing transverse rectus abdominus myocutaneous (msTRAM) flaps coupled with an accompanying inguinal lymph node (43). In a retrospective study of 27 patients, Akita et al. (2017) showed that patients who receive VLNT with autologous breast repair experience a larger reduction in extremity circumference compared to those who only receive VLNT (44). These findings suggest that autologous breast repair alone may have an independent or synergistic effect on lymphedema reduction.

A limitation of VLNT is the risk of donor site lymphedema. A systematic review by Demiri et al. (2018) showed that donor site lower extremity lymphedema occurred at an incidence of $1.6 \%$ in a population of 189 (45). Scaglioni et al. (2018) found a similar incidence of donor site lymphedema in patients whose inguinal lymph nodes were transferred, but a higher rate of $13.2 \%$ in patients whose donor site was the lateral thoracic node (46). Conversely, Maldonado et al. (2017) performed a prospective study of 100 supraclavicular VLNTs and had a donor site lymphedema rate of $0 \%$ over an average 11 month follow-up (47).

Reverse lymphatic mapping prior to surgery has been proposed as a technique to prevent donor site lymphedema following VLNT (48). This method allows the surgeon to visualize the donor site lymph nodes intraoperatively and actively avoid lymph nodes that drain the extremities, thereby lowering the risk of iatrogenic donor site lymphedema.

\section{Ablative therapy}

In advanced stages of lymphedema, where extensive interstitial tissue fibrosis has occurred, physiologic therapies may not provide sufficient volume reduction. "Rescue" procedures such as ablative surgical procedures can be used at this stage to improve aesthetic outcome, although they do not address the root cause of lymphedema. Commonly used ablative procedures include subcutaneous excisional procedures and suction-assisted lipectomy.

\section{Excisional procedures}

Therapeutic excisional techniques have been well described since 1912, particularly for the treatment of elephantiasis (49-51). One of the well-known procedures today is the Charles procedure, which involves radical circumferential excision of subcutaneous tissue followed by full thickness skin grafting. van der Walt et al. (2009) further modernized this technique to include negative pressure wound therapy and delayed skin grafting, in an effort to improve graft take and wound recovery (52). This is now known as the modified Charles procedure. Despite its long history of use, there have been no prospective studies investigating the outcomes of subcutaneous excision procedures with detailed long-term follow-up. Retrospective studies have reported positive outcomes in volume reduction, albeit with limited 
sample sizes, and confounding results due to combination with other physiologic procedures $(53,54)$. Subcutaneous excisional procedures are generally preserved only for advanced lymphedema due to its poor aesthetic outcome, risk of lymphedema recurrence, infection, wound break down, and in severe cases amputation (55).

\section{Liposuction}

Liposuction is a minimally-invasive, yet effective method of lymphedema treatment. The technique involves removal of subcutaneous adipose tissue from the lymphedematous limb using a suction-assisted lipectomy cannula. The target population are patients with chronic lymphedema whose pitting edema has been replaced by fatty deposits (56). Patient satisfaction with the technique is high, as patients are encouraged to return to their daily routine with a short recovery time $(57,58)$. Furthermore, it can be performed as an adjunctive procedure to physiologic treatments such as LVA or VLNT to improve outcomes (59).

The use of liposuction for lymphedema was first popularized by Brorson and Svensson (1998) who examined the feasibility of combined liposuction and compression garment as a treatment for lymphedema (60). Their prospective study of 28 patients showed a $104 \%$ reduction in limb volume relative to the unaffected side with liposuction and postoperative compressive garments, compared to a $47 \%$ reduction for patients treated with compressive garments alone (60). More recent studies have shown similarly positive outcomes. In a prospective study of 105 patients, Hoffner et al. (2018) showed an average lymphedematous extremity volume reduction of $117 \%$ compared to the unaffected limb 5 years following liposuction and compressive garment treatment (61). Agko et al. (2018) demonstrated a limb circumference reduction of $96.4 \%$ following VLNT and liposuction, compared to $37.9 \%$ with VLNT alone, indicating effectiveness of combining liposuction with physiologic procedures (59). Decreased infection risk following combined therapy has been reported as well $(59,62)$. The primary limitation of liposuction therapy is that patients must wear compressive garments indefinitely to maintain the reduced limb volume (63).

Proper follow-up of liposuction therapy for lymphedema involves a multidisciplinary approach to treatment, involving the surgeons, physiotherapists, and a compliant patient (64). Patients have reported increased quality of life following liposuction treatment, despite having to wear compressive garments long-term as part of their treatment
$(65,66)$. This suggests that the cosmetic and functional benefits of liposuction outweigh the burden caused by lifelong compression therapy. The indications, advantages, and disadvantages of liposuction and each aforementioned surgical technique have been summarized in Table 2.

\section{Combined surgical therapy}

Recent reports of combined surgical therapy have demonstrated that performing physiological and ablative procedures together may have benefits beyond improved volume reduction (Table 3). Performing a physiological procedure such as VLNT or LVA in addition to liposuction has been shown to reduce the need for continuous compressive therapy following liposuction. Granzow et al. (2014) and Nicoli et al. (2015) both reported that performing a staged procedure of liposuction followed by VLNT allowed patients wear compressive garment less frequently and still maintain reduced arm volume and improved skin tonicity $(62,67)$. Campisi et al. (2017) demonstrated that this is the case for LVA as well, as patients who received a combination of LVA with liposuction were able to maintain limb volume despite only wearing compression garment at night time (68). Eleven percent of the patient cohort were able to discontinue compressive garment use completely over 12 months post-operation (68). While physiological procedures are most effective in early stages of lymphedema, the addition of ablative therapy can render them effective therapeutic options for late stage lymphedema as well. In a retrospective study of 68 patients with International Society of Lymphology stage III lymphedema, Ciudad et al. (2019) reported that the combination of lymph node transfer with subcutaneous excisional procedures achieved significant limb circumference reduction and a decreased incidence of infectious episodes (Table 1) (69). Additionally, all patients in this study were able to discontinue compressive garment use 8 months after surgery (69).

\section{Limitations}

In this narrative review, we did not perform a statistical analysis of outcomes from the discussed studies. A metaanalysis of outcomes would allow for comparison of the efficacy of each technique, as well as a comparison between isolated and combined techniques. Furthermore, literature written in languages other than English were not included in this review. 
Table 2 Options for surgical therapy of lymphedema

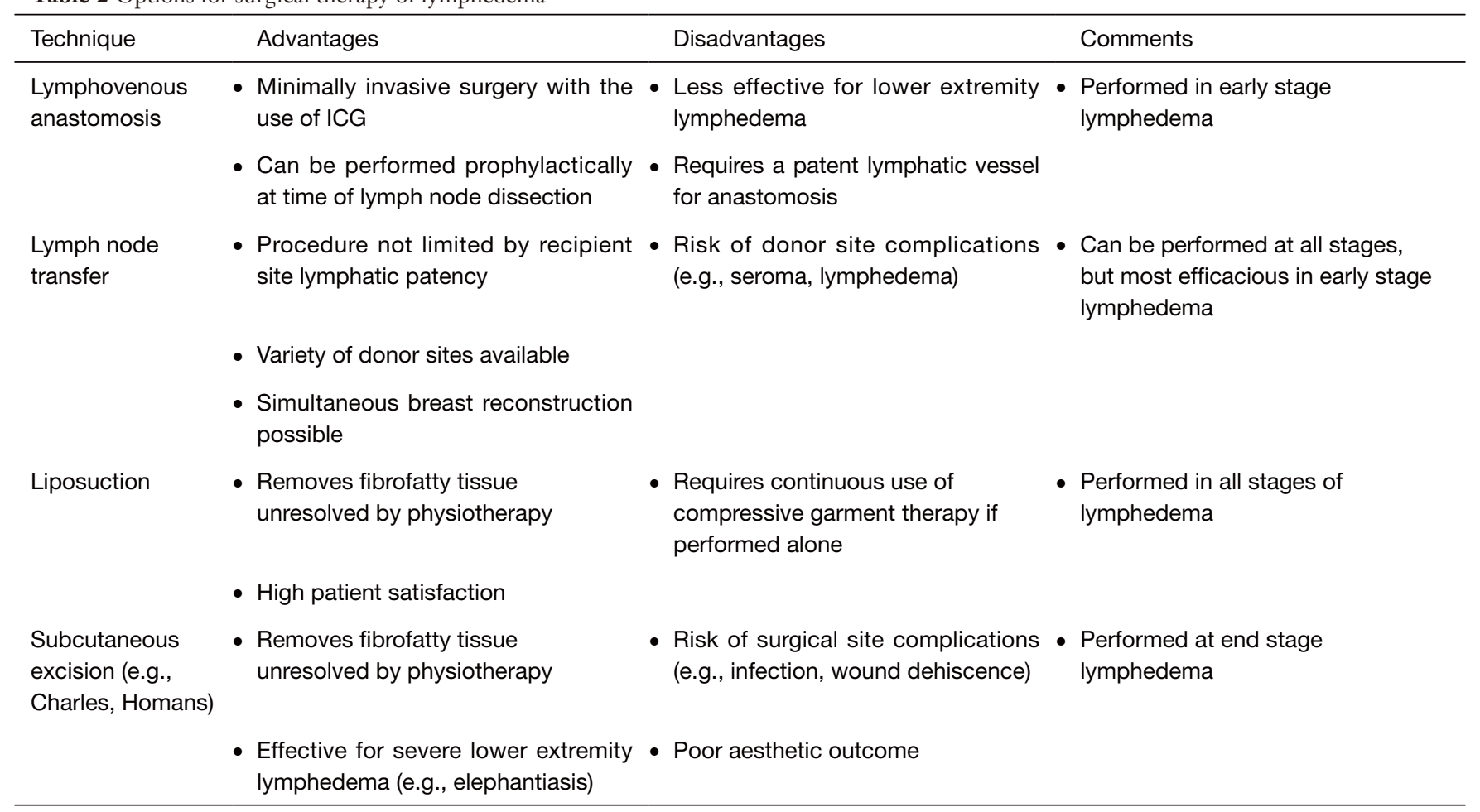

ICG, indocyanine green.

Table 3 Reported combined therapies

\begin{tabular}{lll}
\hline Technique & Advantages over isolated procedure & Reporting studies \\
\hline LVA/LNT + Liposuction & - Improved volume reduction & • Leppäpuska et al. (2019) \\
& - Improved aesthetic outcome & - Agko et al. (2018) \\
& - Reduced requirement of compressive garment therapy & - Campisi et al. (2017) \\
& & - Nicoli et al. (2015) \\
$\begin{array}{l}\text { LNT + subcutaneounzow et al. (2014) } \\
\text { (e.g., Charles, Homan procedures) }\end{array}$ & - Improved volume reduction & C Ciudad et al. (2019) \\
& - Reduced requirement of compressive garment therapy &
\end{tabular}

LVA, lymphovenous anastomosis; LNT, lymph node transfer.

\section{Conclusions}

Surgical management of lymphedema has evolved in the past several decades, alongside advances in microsurgical techniques. The combination of microsurgical therapy such as VLNT and LVA with ablative procedures have provided patients with potentially improved functional outcomes and quality of life. Nonetheless, lymphedema remains to be a condition with progressive symptoms that surgeons and patients alike find difficult to manage. Further clinical studies with prospective design, larger patient numbers, and prolonged follow-up will help clarify treatment algorithms and improve outcomes.

\section{Acknowledgments}

Funding: None. 


\section{Footnote}

Provenance and Peer Review: This article was commissioned by the Guest Editors (Xiaona Lu, Antonio Jorge Forte) for the series "Lymphedema" published in Gland Surgery. The article was sent for external peer review organized by the Guest Editors and the editorial office.

Conflicts of Interest: All authors have completed the ICMJE uniform disclosure form (available at http://dx.doi. org/10.21037/gs.2020.03.14). The series "Lymphedema" was commissioned by the editorial office without any funding or sponsorship. XL serves as the unpaid editorial board member of Gland Surgery from Aug 2019 to Jul 2021 and served as the unpaid Guest Editor of the series. The other authors have no other conflicts of interest to declare.

Ethical Statement: The authors are accountable for all aspects of the work in ensuring that questions related to the accuracy or integrity of any part of the work are appropriately investigated and resolved.

Open Access Statement: This is an Open Access article distributed in accordance with the Creative Commons Attribution-NonCommercial-NoDerivs 4.0 International License (CC BY-NC-ND 4.0), which permits the noncommercial replication and distribution of the article with the strict proviso that no changes or edits are made and the original work is properly cited (including links to both the formal publication through the relevant DOI and the license). See: https://creativecommons.org/licenses/by-nc$\mathrm{nd} / 4.0 /$.

\section{References}

1. Tiwari A, Cheng KS, Button M, et al. Differential diagnosis, investigation, and current treatment of lower limb lymphedema. Arch Surg 2003;138:152-61.

2. Grada AA, Phillips TJ. Lymphedema: Pathophysiology and clinical manifestations. J Am Acad Dermatol 2017;77:1009-20.

3. Catherine L. McGuinness KGB. Chapter 49 Lymphedema. In: Hallett JLM, Earnshaw JJ, Reekers JA, et al. editors. Comprehensive Vascular and Endovascular Surgery 2ed. Mosby, 2009:862-75.

4. Smeltzer DM, Stickler GB, Schirger A. Primary lymphedema in children and adolescents: a follow-up study and review. Pediatrics 1985;76:206-18.
5. Grada AA, Phillips TJ. Lymphedema: Diagnostic workup and management. J Am Acad Dermatol 2017;77:995-1006.

6. Cormier JN, Askew RL, Mungovan KS, et al. Lymphedema beyond breast cancer: a systematic review and meta-analysis of cancer-related secondary lymphedema. Cancer 2010;116:5138-49.

7. Ezzo J, Manheimer E, McNeely ML, et al. Manual lymphatic drainage for lymphedema following breast cancer treatment. Cochrane Database Syst Rev 2015:CD003475.

8. Melam GR, Buragadda S, Alhusaini AA, et al. Effect of complete decongestive therapy and home program on health- related quality of life in post mastectomy lymphedema patients. BMC Womens Health 2016;16:23.

9. Mondry TE, Riffenburgh RH, Johnstone PA. Prospective trial of complete decongestive therapy for upper extremity lymphedema after breast cancer therapy. Cancer J 2004;10:42-8; discussion 17-9.

10. Lasinski BB, McKillip Thrift K, Squire D, et al. A systematic review of the evidence for complete decongestive therapy in the treatment of lymphedema from 2004 to 2011. PM R 2012;4:580-601.

11. Shih YC, Xu Y, Cormier JN, et al. Incidence, treatment costs, and complications of lymphedema after breast cancer among women of working age: a 2-year follow-up study. J Clin Oncol 2009;27:2007-14.

12. Head LK, Momtazi M. Economics of Lymphovenous Bypass. Plast Reconstr Surg 2019;144:751e-9e.

13. Homans J. The treatment of elephantiasis of the legs - A preliminary report. N Engl J Med 1936;215:1099-104.

14. Dellon AL, Hoopes JE. Charles Procedure for Primary Lymphedema - Long-Term Clinical Results. Plast Reconstr Surg 1977;60:589-95.

15. Nielubowicz J, Olszewski W. Experimental lymphovenous anastomosis. Br J Surg 1968;55:449-51.

16. Nielubowicz J, Olszewski W. Surgical lymphaticovenous shunts in patients with secondary lymphoedema. Br J Surg 1968;55:440-2.

17. Jacobson JH, 2nd, Suarez EL. Microvascular surgery. Dis Chest 1962;41:220-4.

18. Koshima I, Inagawa K, Urushibara K, et al. Supermicrosurgical Lymphaticovenular Anastomosis for the Treatment of Lymphedema in the Upper Extremities. $\mathrm{J}$ reconstr Microsurg 2000;16:437-42.

19. Chang DW. Lymphaticovenular bypass for lymphedema management in breast cancer patients: a prospective study. Plast Reconstr Surg 2010;126:752-8.

20. Yamamoto T, Narushima M, Yoshimatsu H, et al. 
Minimally invasive lymphatic supermicrosurgery (MILS): indocyanine green lymphography-guided simultaneous multisite lymphaticovenular anastomoses via millimeter skin incisions. Ann Plast Surg 2014;72:67-70.

21. Shih HB, Shakir A, Nguyen DH. Use of Indocyanine Green-SPY Angiography for Tracking Lymphatic Recovery After Lymphaticovenous Anastomosis. Ann Plast Surg 2016;76 Suppl 3:S232-7.

22. Rosian K, Stanak M. Efficacy and safety assessment of lymphovenous anastomosis in patients with primary and secondary lymphoedema: A systematic review of prospective evidence. Microsurgery 2019;39:763-72.

23. Tourani SS, Taylor GI, Ashton MW. Long-Term Patency of Lymphovenous Anastomoses: A Systematic Review. Plast Reconstr Surg 2016;138:492-8.

24. Scaglioni MF, Fontein DBY, Arvanitakis M, et al. Systematic review of lymphovenous anastomosis (LVA) for the treatment of lymphedema. Microsurgery 2017;37:947-53.

25. Chang DW, Suami H, Skoracki R. A prospective analysis of 100 consecutive lymphovenous bypass cases for treatment of extremity lymphedema. Plast Reconstr Surg 2013;132:1305-14.

26. Boccardo FM, Casabona F, Friedman D, et al. Surgical prevention of arm lymphedema after breast cancer treatment. Ann Surg Oncol 2011;18:2500-5.

27. Jørgensen MG, Toyserkani NM, Sorensen JA. The effect of prophylactic lymphovenous anastomosis and shunts for preventing cancer-related lymphedema: a systematic review and meta-analysis. Microsurgery 2018;38:576-85.

28. Cheng MH, Loh CYY, Lin CY. Outcomes of Vascularized Lymph Node Transfer and Lymphovenous Anastomosis for Treatment of Primary Lymphedema. Plast Reconstr Surg Glob Open 2018;6:e2056.

29. Winters H, Tielemans HJP, Hameeteman M, et al. The efficacy of lymphaticovenular anastomosis in breast cancer-related lymphedema. Breast Cancer Res Treat 2017;165:321-7.

30. Chung JH, Baek SO, Park HJ, et al. Efficacy and patient satisfaction regarding lymphovenous bypass with sleevein anastomosis for extremity lymphedema. Arch Plast Surg 2019;46:46-56.

31. Clodius L, Smith PJ, Bruna J, et al. The lymphatics of the groin flap. Ann Plast Surg 1982;9:447-58.

32. Suami H, Chang DW. Overview of surgical treatments for breast cancer-related lymphedema. Plast Reconstr Surg 2010;126:1853-63.

33. Schaverien MV, Badash I, Patel KM, et al. Vascularized Lymph Node Transfer for Lymphedema. Semin Plast Surg 2018;32:28-35.
34. Ito R, Suami H. Overview of lymph node transfer for lymphedema treatment. Plast Reconstr Surg 2014;134:548-56.

35. Liu HL, Pang SY, Lee CC, et al. Orthotopic transfer of vascularized groin lymph node flap in the treatment of breast cancer-related lymphedema: Clinical results, lymphoscintigraphy findings, and proposed mechanism. J Plast Reconstr Aesthet Surg 2018;71:1033-40.

36. Suami H, Scaglioni MF, Dixon KA, et al. Interaction between vascularized lymph node transfer and recipient lymphatics after lymph node dissection-a pilot study in a canine model. J Surg Res 2016;204:418-27.

37. Lin CH, Ali R, Chen SC, et al. Vascularized groin lymph node transfer using the wrist as a recipient site for management of postmastectomy upper extremity lymphedema. Plast Reconstr Surg 2009;123:1265-75.

38. Cheng MH, Huang JJ, Nguyen DH, et al. A novel approach to the treatment of lower extremity lymphedema by transferring a vascularized submental lymph node flap to the ankle. Gynecol Oncol 2012;126:93-8.

39. Cheng MH, Chen SC, Henry SL, et al. Vascularized groin lymph node flap transfer for postmastectomy upper limb lymphedema: flap anatomy, recipient sites, and outcomes. Plast Reconstr Surg 2013;131:1286-98.

40. Becker C, Assouad J, Riquet M, et al. Postmastectomy lymphedema: long-term results following microsurgical lymph node transplantation. Ann Surg 2006;243:313-5.

41. Batista BN, Germain M, Faria JC, et al. Lymph node flap transfer for patients with secondary lower limb lymphedema. Microsurgery 2017;37:29-33.

42. Leppäpuska IM, Suominen E, Viitanen T, et al. Combined Surgical Treatment for Chronic Upper Extremity Lymphedema Patients: Simultaneous Lymph Node Transfer and Liposuction. Ann Plast Surg 2019;83:308-17.

43. Saaristo AM, Niemi TS, Viitanen TP, et al. Microvascular breast reconstruction and lymph node transfer for postmastectomy lymphedema patients. Ann Surg 2012;255:468-73.

44. Akita S, Tokumoto H, Yamaji Y, et al. Contribution of Simultaneous Breast Reconstruction by Deep Inferior Epigastric Artery Perforator Flap to the Efficacy of Vascularized Lymph Node Transfer in Patients with Breast Cancer-Related Lymphedema. J Reconstr Microsurg 2017;33:571-8.

45. Demiri E, Dionyssiou D, Tsimponis A, et al. Donor-Site Lymphedema Following Lymph Node Transfer for Breast Cancer-Related Lymphedema: A Systematic Review of the Literature. Lymphat Res Biol 2018;16:2-8. 
46. Scaglioni MF, Arvanitakis M, Chen YC, et al. Comprehensive review of vascularized lymph node transfers for lymphedema: Outcomes and complications. Microsurgery 2018;38:222-9.

47. Maldonado AA, Chen R, Chang DW. The use of supraclavicular free flap with vascularized lymph node transfer for treatment of lymphedema: A prospective study of 100 consecutive cases. J Surg Oncol 2017;115:68-71.

48. Dayan JH, Dayan E, Smith ML. Reverse lymphatic mapping: a new technique for maximizing safety in vascularized lymph node transfer. Plast Reconstr Surg 2015;135:277-85.

49. Dumanian GA, Futrell JW. The Charles procedure: misquoted and misunderstood since 1950. Plast Reconstr Surg 1996;98:1258-63.

50. Miller TA, Wyatt LE, Rudkin GH. Staged skin and subcutaneous excision for lymphedema: a favorable report of long-term results. Plast Reconstr Surg 1998;102:148698; discussion 99-501.

51. Sistrunk WE. Contribution to Plastic Surgery: Removal of Scars by Stages; an Open Operation for Extensive Laceration of the Anal Sphincter; the Kondoleon Operation for Elephantiasis. Ann Surg 1927;85:185-93.

52. van der Walt JC, Perks TJ, Zeeman BJ, et al. Modified Charles procedure using negative pressure dressings for primary lymphedema: a functional assessment. Ann Plast Surg 2009;62:669-75.

53. Karonidis A, Chen HC. Preservation of toes in advanced lymphedema: an important step in the control of infection. Ann Plast Surg 2010;64:446-50.

54. Sapountzis S, Ciudad P, Lim SY, et al. Modified Charles procedure and lymph node flap transfer for advanced lower extremity lymphedema. Microsurgery 2014;34:439-47.

55. Miller TA. Charles procedure for lymphedema: a warning. Am J Surg 1980;139:290-2.

56. Greene AK, Maclellan RA. Operative Treatment of Lymphedema Using Suction-Assisted Lipectomy. Ann Plast Surg 2016;77:337-40.

57. Bolletta A, Di Taranto G, Chen SH, et al. Surgical treatment of Milroy disease. J Surg Oncol 2020;121:175-81.

58. Hoffner M, Bagheri S, Hansson E, et al. SF-36 Shows Increased Quality of Life Following Complete Reduction of Postmastectomy Lymphedema with Liposuction. Lymphat Res Biol 2017;15:87-98.

59. Agko M, Ciudad P, Chen HC. Staged surgical treatment of extremity lymphedema with dual gastroepiploic vascularized lymph node transfers followed by suctionassisted lipectomy-A prospective study. J Surg Oncol 2018;117:1148-56.
60. Brorson H, Svensson H. Liposuction combined with controlled compression therapy reduces arm lymphedema more effectively than controlled compression therapy alone. Plast Reconstr Surg 1998;102:1058-67; discussion 1068.

61. Hoffner M, Ohlin K, Svensson B, et al. Liposuction Gives Complete Reduction of Arm Lymphedema following Breast Cancer Treatment-A 5-year Prospective Study in 105 Patients without Recurrence. Plast Reconstr Surg Glob Open 2018;6:e1912.

62. Granzow JW, Soderberg JM, Dauphine C. A novel twostage surgical approach to treat chronic lymphedema. Breast J 2014;20:420-2.

63. Schaverien MV, Munnoch DA, Brorson H. Liposuction Treatment of Lymphedema. Semin Plast Surg 2018;32:42-7.

64. Boyages J, Kastanias K, Koelmeyer LA, et al. Liposuction for Advanced Lymphedema: A Multidisciplinary Approach for Complete Reduction of Arm and Leg Swelling. Ann Surg Oncol 2015;22 Suppl 3:S1263-70.

65. Klernäs P, Johnsson A, Boyages J, et al. Quality of Life Improvements in Patients with Lymphedema After Surgical or Nonsurgical Interventions with 1-Year FollowUp. Lymphat Res Biol 2019. [Epub ahead of print].

66. Brorson H, Ohlin K, Olsson G, et al. Quality of life following liposuction and conservative treatment of arm lymphedema. Lymphology 2006;39:8-25.

67. Nicoli F, Constantinides J, Ciudad P, et al. Free lymph node flap transfer and laser-assisted liposuction: a combined technique for the treatment of moderate upper limb lymphedema. Lasers Med Sci 2015;30:1377-85.

68. Campisi CC, Ryan M, Boccardo F, et al. Fibro-LipoLymph-Aspiration With a Lymph Vessel Sparing Procedure to Treat Advanced Lymphedema After Multiple Lymphatic-Venous Anastomoses: The Complete Treatment Protocol. Ann Plast Surg 2017;78:184-90.

69. Ciudad P, Agko M, Huang TCT, et al. Comprehensive multimodal surgical treatment of end-stage lower extremity lymphedema with toe management: The combined Charles,' Homan's, and vascularized lymph node transfer (CHAHOVA) procedures. J Surg Oncol 2019;119:430-8.

Cite this article as: Park KE, Allam O, Chandler L, Mozzafari MA, Ly C, Lu X, Persing JA. Surgical management of lymphedema: a review of current literature. Gland Surg 2020;9(2):503-511. doi: 10.21037/gs.2020.03.14 